\title{
Foreword to the Original Edition
}

Fire was the first natural force and source of energy to be tamed by human beings. Heating and food preparation were two early uses of fire. Pretechnological food gatherers, hunters, and herders also employed fire to manage plant and animal life. In modern land-use practice, however, fire has been regarded until very recently as an entirely destructive force to be suppressed by all means and at all times.

Harold Biswell was among those few far-sighted ecologists who realized very early in his professional career that wellregulated fire can play a beneficial role today as it did in earlier times. After overcoming much prejudice and fierce opposition, he was the first in California to show, almost single-handedly, how fire can be turned through prescribed burning from a cruel master into a good servant. This book provides us with the testimony of his accomplishments over 40 years of thorough and persistent study, experimentation and observation, teaching, training, and demonstration of prescribed burning and vegetation management in California wildlands. It differs from other works on fire ecology and management by the unique, personal message it conveys-that is, it blends scientific ecological knowledge with the wisdom and expertise derived from long practical experience and true insight.

He has laid the foundations for an overall reappraisal of the role of fire in the California wildlands, not only in such areas as wildlife conservation but also for forestry, livestock production, nature conservation, and natural resources in general. This 
work culminated in the development of the science and art of prescribed burning, which is described in this book in a clear, concise, and straightforward way with numerous, wellillustrated examples. Biswell presents his material not as isolated scientific and ecological techniques, but as imbedded within a broad range of interrelated physical, biological, ecological, socioeconomic, and cultural contexts. His basic philosophy and guideline is to work in harmony with nature and not to violate it, as, by contrast, do the futile attempts to virtually exclude fire. In this way, without specifically mentioning it, he applies the holistic landscape ecology approach that so strongly recognizes the need to create a viable symbiosis between the natural and human elements in wildlands.

Biswell's arguments derive strength from his long, active, and intimate involvement with all phases and scales of prescribed burning, enabling him to persuade his students (some of whom later became leaders in this field), as well as many professional land managers, users, and decision makers, of the value of the approach.

I studied under Biswell as a visiting research scientist from Israel in the late fifties, when he was called "Doc" by his students and admirers and frequently introduced as "Harry the Torch" or "Dr. Burnwell." Like my colleague, Dr. Liacos from Greece, I was highly impressed by his work, and we realized that the principles derived from it have far-reaching implications for the Mediterranean region, with its similar drysummer fire climate and comparable vegetation types. Since then we have zealously spread the message of the benefits to be derived from controlled fire and fuel management in the Mediterranean Basin. In this region, the prejudices and misconceptions about the function of fire, and the constraints on initiating innovative research on the use of fire in enlightened management of wildlands vegetation, are even stronger than they were in California. In contrast to the instructive example of control burning by Indians in California, as well as by aborigines in Australia, fire has been-and still is-abused by Mediterranean pastoralists. This destructive practice, along with uncontrolled grazing, has caused the important role of fire as a selective force in the evolution of Mediterranean vegetation 
and in the maintenance of its productivity and diversity to be completely overlooked. Judged, like goat grazing, from its ill effects when abused, fire is regarded as wholly condemnable at all times and in all instances, and its controlled use as an effective means for fuel reduction is rejected. Even its use for research and experimentation is prohibited in many Mediterranean countries. Not only foresters but also most conservationists are fiercely opposed to prescribed burning in nature reserves and parks because they believe that it may endanger a much cherished, but illusory, sclerophyll forest climax (that is, the final stage of ecological succession in broad-leaf forests). However, the threats from destructive wildfires in dense and highly flammable pine and oak forests and shrub thickets are not less severe than in California. At the same time, the communication gap between academic researchers and public and private land managers is even greater than in California: the researchers either do not know about the pressing problems of the land managers or do not bother to present their results in a comprehensible and applicable way; and the land managers are not aware of, or are not willing to make use of, relevant new research information and management techniques. For these reasons, this unique book, although written from a California perspective, should be of great value to a broad international audience, but especially to Mediterranean peoples.

I am convinced that this book will serve as a vital source of information and inspiration for all-in California and elsewhere-who care about the fate of their wildlands.

Zev Naveh

Professor of Landscape Ecology Technion-Israel Institute of Technology

Haifa 
